\title{
Review \\ Inducible Liver Cancer Models in Transgenic Zebrafish to Investigate Cancer Biology
}

\author{
Ai Qi Lee, Yan Li and Zhiyuan Gong*
}

check for updates

Citation: Lee, A.Q.; Li, Y.; Gong, Z. Inducible Liver Cancer Models in Transgenic Zebrafish to Investigate Cancer Biology. Cancers 2021, 13, 5148 . https://doi.org/10.3390/ cancers13205148

Academic Editors: Eleanor Y. Chen and Myron Ignatius

Received: 24 September 2021

Accepted: 9 October 2021

Published: 14 October 2021

Publisher's Note: MDPI stays neutral with regard to jurisdictional claims in published maps and institutional affiliations.

Copyright: (C) 2021 by the authors. Licensee MDPI, Basel, Switzerland. This article is an open access article distributed under the terms and conditions of the Creative Commons Attribution (CC BY) license (https:/ / creativecommons.org/licenses/by/ $4.0 /)$.
Department of Biological Sciences, National University of Singapore, Singapore 119077, Singapore; aiqi@nus.edu.sg (A.Q.L.); dbsliya@nus.edu.sg (Y.L.)

* Correspondence: dbsgzy@nus.edu.sg

Simple Summary: Primary liver cancer ranks amongst the top ten cancers in frequency and mortality, with its global prevalence continuing to increase. Chemotherapy response remains poor and many therapies result in adverse side effects. The use of transgenic animal models that have high disease reproducibility provides opportunities to study cancer events that are difficult to study in human patients. Other than well-established mouse models in cancer research, now there is an increasing interest in using zebrafish to model various cancers. This review summarises the various oncogene transgenic zebrafish models for hepatocellular carcinoma (HCC) our laboratory has established, and the subsequent findings about liver cancer biology by using these transgenic models. In particular, most of our transgenic models employed chemically induced oncogene expression, allowing for temporal control and study of tumour initiation and regression. Investigation into these models reveals activation of tumorigenic pathways, inflammation, male-bias severity and skeletal musclewasting, characteristic of human HCC. Some of the models are also useful in screening for novel anti-metastatic drugs and evaluating the tumorigenic ability of environmental toxicants. The findings presented here demonstrate the utility of the zebrafish models for the further investigation of cancer biology and the development of novel and improved therapies.

Abstract: Primary liver cancer is one of the most prevalent and deadly cancers, which incidence continues to increase while treatment response remains poor; thus, in-depth understanding of tumour events is necessary to develop more effective therapies. Animal models for liver cancer are powerful tools to reach this goal. Over the past decade, our laboratory has established multiple oncogene transgenic zebrafish lines that can be robustly induced to develop liver cancer. Histological, transcriptomic and molecular analyses validate the use of these transgenic zebrafish as experimental models for liver cancer. In this review, we provide a comprehensive summary of our findings with these inducible zebrafish liver cancer models in tumour initiation, oncogene addiction, tumour microenvironment, gender disparity, cancer cachexia, drug screening and others. Induced oncogene expression causes a rapid change of the tumour microenvironment such as inflammatory responses, increased vascularisation and rapid hepatic growth. In several models, histologically-proven carcinoma can be induced within one week of chemical inducer administration. Interestingly, the induced liver tumours show the ability to regress when the transgenic oncogene is suppressed by the withdrawal of the chemical inducer. Like human liver cancer, there is a strong bias of liver cancer severity in male zebrafish. After long-term tumour progression, liver cancer-bearing zebrafish also show symptoms of cancer cachexia such as muscle-wasting. In addition, the zebrafish models have been used to screen for anti-metastasis drugs as well as to evaluate environmental toxicants in carcinogenesis. These findings demonstrated that these inducible zebrafish liver cancer models provide rapid and convenient experimental tools for further investigation of fundamental cancer biology, with the potential for the discovery of new therapeutic approaches.

Keywords: liver cancer; hepatocellular carcinoma (HCC); transgenic; sex disparity; tumour regression; cancer cachexia; metastasis; chemical screen; toxicology; zebrafish 


\section{Introduction}

Based on global cancer statistics in 2020, primary liver cancer was found to be the sixth most frequent type of cancer and ranked in third place for cancer mortality [1]. Its global incidence also continues to rise, with a study on liver cancer etiology showing that diagnosed cases have increased 114\% from 1990 to 2016 [2]. For treatment of hepatocellular carcinoma (HCC), the most prevalent form of primary liver cancer, response to chemotherapy remains poor and the majority of therapies come with multiple adverse side effects [3,4]. The study and in-depth understanding of liver cancer initiation, progression and its related events is, hence, crucial for the discovery and development of preventive treatment and targeted cancer therapeutics with minimal side effects.

Animal models of liver cancer or HCC provide an invaluable way to study the disease. Since human liver cancers are asymptomatic at the early stages, presenting as other forms of liver disease instead [5], cancer is usually diagnosed only at later stages where cancer events such as tumour initiation and early progression cannot be studied; therefore, investigation of these events is largely dependent on using in vitro and experimental animal models. Activation and inhibition experiments, as well as drug screening, can also be performed easily in these models, allowing for the study of cancer events and the discovery of novel therapeutic drugs. Furthermore, different tissues and organs in the organism can be examined to study how liver tumours and liver cancer affect their function. In our laboratory, zebrafish are used as a model for liver tumours and HCC.

Due to its year-round availability, high fecundity, transparent embryos/larvae, and rapid development, the humble zebrafish has become an excellent vertebrate model for developmental and disease studies [6]. The advantages of utilising zebrafish as experimental models include, but are not limited to, the visualization of gene expression in a whole, intact organism via in situ hybridisation of embryos and high resolution live-imaging of fluorescence-tagged proteins or cells in a living vertebrate [7]. Robust genetic manipulation by microinjection of transposon and CRISPR/Cas9 systems into the one-cell embryos has allowed the generation of numerous transgenic genome-edited zebrafish lines [8].

Besides being used to study vertebrate development, to date, the zebrafish has been widely used to model numerous human diseases, including various cancers such as melanoma and leukemia $[9,10]$. These established models show significant phenotypic similarity with the human conditions. There is a surprising level of conservation across the two species despite the obvious evolutionary distance between zebrafish and humans. Barbazuk et al. discovered a high level of conserved synteny between the two species [11], while Howe et al. show that $71.4 \%$ of human genes have at least one obvious orthologue in the zebrafish, with orthologues for over $80 \%$ of human disease genes [12]. Several in-depth reviews on zebrafish as human disease models have been published [13-15], including one on using the Zebrafish Model Organism Database (ZFIN) to facilitate human disease research in zebrafish [16], and are cited here should the reader be interested in this topic.

Many zebrafish models of liver cancer have been established in the past decade or so. The available transgenic models usually overexpress mutant forms of an oncogene or gene that is known to be involved in HCC, such as $\beta$-catenin [17], endothelin 1 [18], ubiquitinlike with PHD and RING finger domains 1 [19], and hepatitis virus proteins [20,21]. Clonal zebrafish lines have been established to allow for transplantable hepatic tumours, overcoming the previous issue of non-reproducibility of carcinogen-induced tumours [22]. More recently, several authors have also established xenograft tumour models of HCC using human HCC cell lines [23,24].

As comprehensive reviews of the various established liver cancer models in zebrafish have been recently published $[25,26]$, this paper will not attempt to duplicate the effort. Instead, we will focus on the zebrafish liver cancer models that our lab has established in the past decade, our efforts to characterise and validate these models as well as novel findings about tumour initiation, progression and regression events from these models. 


\section{Beginning of Our Liver Cancer Journey}

Our first foray into liver cancer started with the generation of carcinogen-induced hepatic tumours, which had previously been reported in mice [27,28] as well as in zebrafish [29-31]. Zebrafish were exposed to known carcinogens, 7,12-dimethylbenz(a)anthracene and dibenzo (a,l)pyrene, and were sampled 6-12 months after carcinogen exposure. Histological and DNA microarray analyses of these carcinogen-induced liver tumours showed that these zebrafish tumours were highly similar to human liver tumours not only at the histopathological level but also at the transcriptomic level as compared to other human tumour types. The transcriptomic data also showed the dysregulation of functional groups and molecular pathways which are seen to be frequently altered in human liver cancers. Moreover, the expression profiles of overlapping genes between human and zebrafish liver tumours correlated with tumour grade and progression $[32,33]$. The conservation between zebrafish and human liver tumours added to our confidence that the zebrafish could be used as a liver cancer model to study cancer-related events.

However, carcinogen-induced liver tumours generally take a long time ( $>6$ months) to form. These tumours tended to be highly variable from one individual to another and are likely due to the alteration of different molecular pathways. In order to generate a more robust and reliable model to ensure reproducibility in studies, we adopted a genetic approach to establish transgenic zebrafish models for HCC by overexpression of selected oncogenes.

\section{Established Transgenic Liver Cancer Models}

\subsection{Constitutive Oncogene Expression Model}

Our first transgenic zebrafish liver cancer model constitutively expressed the hyperactive mutant oncogene $\mathrm{kras}^{\mathrm{V} 12}$ under the control of the liver-specific promoter, fabp $10 \mathrm{a}$ (Figure 1A) [34]. KRAS is part of the RAS/MAPK pathway, a signalling pathway that plays a prominent role in cell proliferation and differentiation. This oncogene has long been found to be mutated, and more recently, amplified, in various types of human cancers, such as colorectal and lung cancer [35-40]. Even though RAS mutations are rare in human HCC, RAS activation occurs despite the absence of its mutation [41]. Our transgenic model provided the opportunity to study the effect of liver-specific expression of oncogenic kras ${ }^{V 12}$ and its contribution to liver cancer in vivo as there was no mice model using Kras to drive liver tumorigenesis at that time.

Histological analysis of hepatic tumours confirmed the presence of hyperplasia, adenoma and HCC in the $\mathrm{kras}^{\mathrm{V12}}$ model [34]. The tumours also showed dysregulation of key signalling pathways seen in human HCC, such as MAPK and Wnt/ $\beta$-catenin pathways, which were confirmed via molecular and transcriptomic analyses. Significant disease stagespecific conservation between the gene signatures of zebrafish and human liver tumours further validated the utility of the $\mathrm{kras}^{\mathrm{V} 12}$ fish as a model for human liver cancer.

This model, however, has several drawbacks. First, early mortality due to heavy tumour burden made it difficult to study long-term cancer progression and to maintain the transgenic line as fish tended to die before sexual maturity. Secondly, constitutive oncogene expression starts from the earliest liver cell differentiation during embryonic development, which rarely happens in human liver cancers and makes it hard to study tumour initiation events. In order to overcome these limitations, we further developed several conditional transgenic models to have inducible oncogene expression in order to temporally control tumour initiation and progression. 


\section{A) Constitutive expression system}

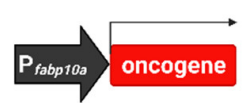

B) Mifepristone-inducible system

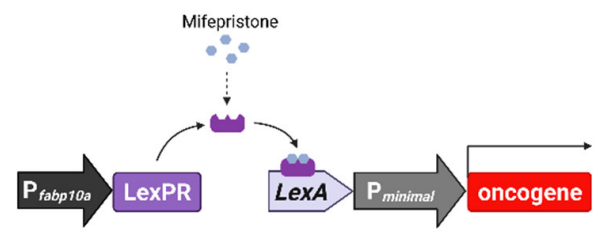

C) Tet-on system

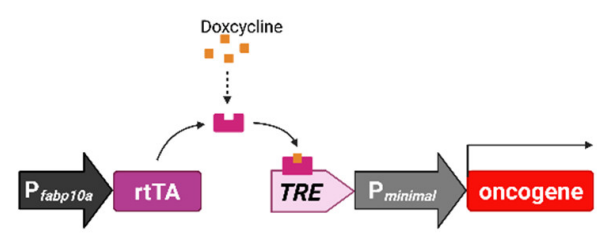

D) Inducible recombination system

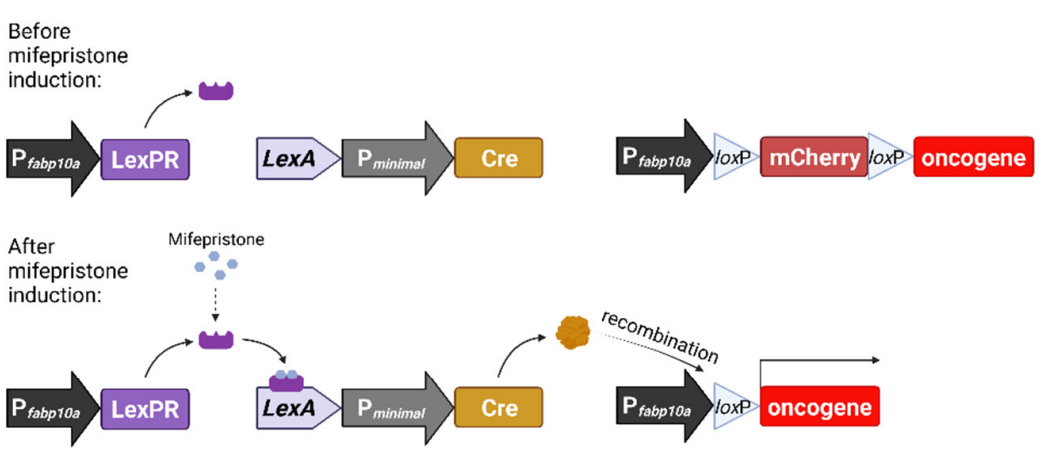

E) Tamoxifen-inducible system

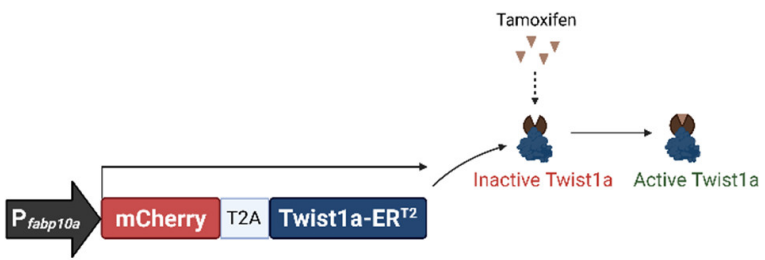

\section{F) Cancer cell lineage tracing system}

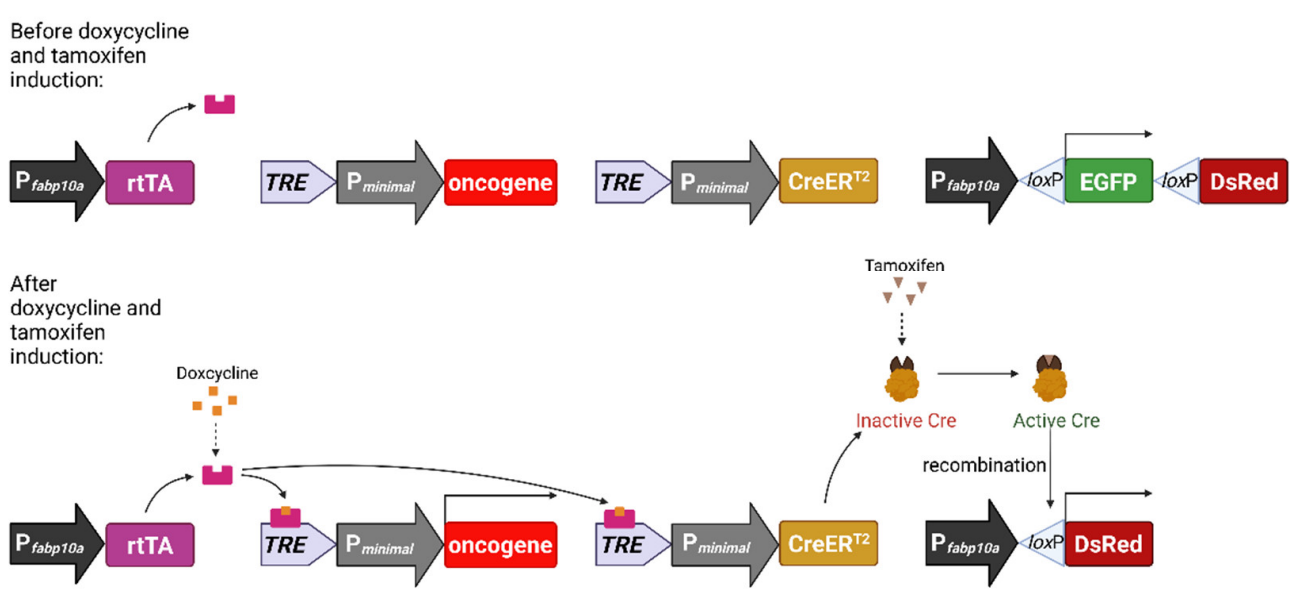

Figure 1. Schematic representation of various inducible systems we used for development of liver cancer models in transgenic zebrafish. (A) Constitutive expression system. Oncogene expression is under direct control of the hepatocytespecific fabp10a promoter, causing oncogene to be constitutively expressed. (B) Mifepristone-inducible system. fabp10a promoter is used to transcribe a chimeric LexPR transactivator, which consists of the DNA binding domain of the bacterial LexA protein, the ligand binding domain of the human progesterone receptor (PR) and the activation domain of human p65 transcription factor. LexPR transactivator is activated by the mifepristone ligand and binds to the LexA operator to activate the transcription of the downstream oncogene. (C) Tet-on system. The reverse tetracycline-controlled transactivator (rtTA) is transcribed by the fabp10a promoter, but it becomes activated only in the presence of doxycycline and, in turn, it binds to the Tet Response Element (TRE) to activate the transcription of downstream oncogene. (D) Inducible recombination system. It incorporates the Cre-loxP components into the mifepristone-inducible system in order to induce permanent oncogene expression via genomic recombination. In this system, mifepristone activates LexPR, which binds the LexA operator to allow the expression of Cre recombinase. Cre recognises loxP sequences and excises the mCherry STOP cassette to permanently activate the downstream oncogene. (E) Tamoxifen-inducible system. A Twist1a-ER ${ }^{\mathrm{T} 2}$ fusion gene (twist1a and ligand binding domain of estrogen receptor [ER]) is constitutively transcribed by fabp10a promoter but the activation of the fusion protein requires the ligand, tamoxifen. T2A is a self-cleavage peptide to allow simultaneous production of two separate proteins. (F) Cancer cell lineage tracing system. Doxycycline activates rtTA, which in turn causes transcription of both $x m r k$ oncogene and CreER ${ }^{\mathrm{T} 2}$. CreER ${ }^{\mathrm{T} 2}$ is activated by tamoxifen and excises the floxed EGFP sequence to cause the change of the expression of fluorescent protein genes. Figure created with BioRender.com (accessed on 23 September 2021). 


\subsection{Chemically Inducible Oncogene and Cytokine Overexpression}

Our first inducible model used the mifepristone-inducible LexPR system to control liver-specific kras ${ }^{V 12}$ expression (Figure 1B) [42,43]. This system allowed us to temporally control, and hence, study tumour initiation and regression; events that are difficult or even near impossible to study in human patients. Mifepristone-treated fish showed dosage and time-dependent tumour frequency and induction. At higher mifepristone concentrations, transgenic zebrafish livers turned hyperplastic after 1 week of induction and progressed to HCC within 4 weeks of treatment, with $100 \%$ penetrance. Western blots and immunohistochemistry confirmed the activation of the Raf-MEK-ERK pathway, while chemical inhibition of ERK and AKT pathways suppressed tumorigenesis in transgenic larvae [43].

Following the successful establishment and validation of the mifepristone-inducible model, our lab went on to generate additional transgenic lines by using another inducible system, the tetracycline-inducible Tet-on system [44], to control kras ${ }^{V 12}$ [45], xmrk [46], and mouse Myc [47] expression in the zebrafish liver (Figure 1C). Xmrk is a hyperactive mutant of fish epidermal growth factor receptor (Egfr) and structurally related to human EGFR [48], which plays a prominent role in human hepatocarcinogenesis and whose overexpression is correlated with poor survival [49]. Similarly, the amplification, and subsequent overexpression, of MYC is also associated with poor prognosis in human HCC [50] and has been shown to cause HCC in murine models [51,52]. All three transgenic lines showed rapid liver enlargement and tumorigenesis upon oncogene induction and the majority of tumours induced in the $\mathrm{kras}^{V 12}$ and $\mathrm{xmrk}$ lines progressed to HCC. The oncogenicity of zebrafish myc orthologs, myca and mycb, was also confirmed by transgenic expression, with myca transgenic zebrafish showing multinodular HCC after prolonged induction [53].

The utilisation of the two inducible transgenic expression systems has the advantage of selectively activating different oncogenes if multiple oncogenes are required in the study. The use of different chemical inducers also has an advantage in the case when any chemical inducer may interfere with downstream experimental analyses. In general, all these inducible oncogene transgenic zebrafish showed dosage- and time-dependent induction of oncogene expression and tumour severity. The induced tumour transformation is rapid and the HCC phenotype could be induced within 1-2 weeks of chemical induction [54]. The temporal induction could be performed at any age such as from 2 weeks old to 8 months old to reliably induce HCC phenotype [46]. In larvae (3-7 days postfertilisation), rapid oncogenic liver growth can be observed immediately after chemical induction and 2D liver size can be quantitatively measured for various bioassays before feeding. The tumour transformation is generally homogenous throughout the liver, which is an advantage for biochemical analyses but is unlikely to be the case in human patients where the cancer originates from one or a few transformed cells and progresses through clonal expansion.

Besides the described oncogene-driven liver cancer models, we have also established a mifepristone-inducible zebrafish line that overexpresses tof $\beta 1 a$ specifically in the liver [55]. The cytokine is of interest because its expression is upregulated in diet-induced nonalcoholic steatohepatitis (NASH) and it might play an important role in the transformation of NASH to HCC. Indeed we found that chronic Tgf $\beta 1$ overexpression induced both HCC and cholangiocarcinoma (CCA), bile duct epithelial cell cancer, with dose-dependent severity. It appears that there was a switch of dominant activated signalling pathways from Smad to Erk during carcinogenesis in hepatocytes while CCA requires concurrent activation of both Smad and Erk pathways [55].

\subsection{Inducible Permanent Oncogene Expression}

In all of the above mentioned inducible transgenic models, the fish had to have constant exposure to the inducing chemical in order to maintain transgene expression. This resulted in the transformation of all liver cells once a chemical inducer is used, which is unlikely to be the case in human cancer. Furthermore, the continued presence of the chemical inducer may also affect subsequent chemical treatment and this is not desired in many experiments, such as drug screening, using these models. To overcome these prob- 
lems, we developed another transgenic model which requires only a short pulse chemical treatment to activate oncogene expression by induction of permanent genomic change. In this model, we combined the mifepristone-inducible $\mathrm{kras}^{V 12}$ model and the Cre/loxP system (Figure 1D) [56]. Like in the previous model, $\mathrm{kras}^{\mathrm{V} 12}$ was controlled by the liverspecific promoter fabp10a, but its transcription is interrupted by loxP sequences flanking an $m$ Cherry-STOP cassette sequence in the new transgenic line. Cre recombinase expression, induced in the presence of mifepristone, excises the STOP cassette sequence, resulting in genomic recombination and the permanent expression of $\mathrm{ras}^{V 12}$. In practice, it was found that Cre-mediated recombination tended to be incomplete. This resulted in distinct tumour nodules within the liver that did not show any mCherry fluorescence, suggesting that nodules were likely formed from clonal proliferation, which more resembled human liver tumours [56].

\subsection{Metastatic Model of HCC}

So far, in all transgenic models we generated by overexpression of a single oncogene, although histologically proven HCC is robustly induced, there was no obvious tumour metastasis. One likely reason is the high severity of the induced primary liver cancer; as it occurs in the whole liver, and these fish may not be able to survive till metastasis stage. Another reason is that tumour metastasis may require the activation of additional molecular pathways. To tackle this issue, we generated another transgenic zebrafish line with mifepristone-induced expression of a gene (twist1a) important in epithelialmesenchyme transition (EMT), the first step of tumour metastasis. The new Twist1a-ER ${ }^{T 2}$ line constitutively expressed liver-specific Twist1a-ER ${ }^{\mathrm{T} 2}$, but activation of the protein only occurs upon tamoxifen treatment (Figure 1E) [57]. When we combined the Twist1a-ER ${ }^{T 2}$ and xmrk transgenic fish, we found that hepatic cells in double transgenic fish showed extensive dissemination from the tumorigenic liver and even long-distance migration to trunk and tail regions [57]. In some fish, the establishment of secondary tumours was also observed [58]. These observations suggested the need for cooperation of oncogene and EMT gene to initiate tumour metastasis in the zebrafish models.

A summary of our established transgenic zebrafish models of liver cancer is presented in Table 1.

\subsection{Histological, Transcriptomic and Molecular Validation}

All of our established models have been extensively validated histologically. In general, zebrafish, rodent, and human liver neoplasms are very similar in histology [32]. Though part of the HCC grading criteria of human HCC does not entirely fit for zebrafish, nuclear factors seen in the disease in both species are highly alike. The most severe tumour grades in humans and zebrafish show the most pronounced nuclear irregularity, hyperchromasia, and obvious nucleoli [32]. 
Table 1. Summary of our transgenic zebrafish models of liver cancer.

\begin{tabular}{|c|c|c|c|c|c|}
\hline Transgene & Transposon System & Inducible System & Permanent Recombination & Tumour Phenotypes * & References \\
\hline \multirow{4}{*}{ kras $^{V 12}$} & Ac/Ds & - & - & $\begin{array}{l}3 \text { mpf: } 36 \% \text { HP } \\
6 \text { mpf: } 22 \% \text { HA } \\
9 \text { mpf: } 26 \% \text { HCC }\end{array}$ & [34] \\
\hline & $\mathrm{Ac} / \mathrm{Ds}$ & LexPR & No & $\begin{array}{l}1 \text { wpi: } 100 \% \text { HP } \\
4 \text { wpi: } 100 \% \text { HCC }\end{array}$ & [43] \\
\hline & None & Tet-on & No & $\begin{array}{c}7 \text { dpi: } 40 \% \text { HCC and } 50-60 \% \text { HA } \\
\text { in males. } 30-40 \% \text { HA and } \\
60-70 \% \text { HP in females. } \\
10 \text { dpi: } 100 \% \text { HCC in males. } \\
70 \% \text { HCC, } 20 \% \text { HA and } 10 \% \text { HP } \\
\text { in females. } \\
\text { 5mpi: } 100 \% \text { multinodular HCC } \\
\text { in males, } 100 \% \text { homogenous } \\
\text { HCC in females. }\end{array}$ & {$[45,59-61]$} \\
\hline & Ac/Ds & LexPR & Yes & $\begin{array}{l}\text { Severity dependent on age of } \\
\text { induction. } \\
\text { Most fish developed mosaic } \\
\text { livers with more than } \\
1 \text { tumour type. }\end{array}$ & [56] \\
\hline$x m r k$ & None & Tet-on & No & $\begin{array}{c}7 \text { dpi: } 50 \% \text { HCC, } 30 \% \text { HA and } \\
20 \% \text { HP in males. } 20 \% \text { HA and } \\
\text { 80\% HP in females. } \\
6 \text { wpi: } 100 \% \text { HCC }\end{array}$ & {$[46,54,62]$} \\
\hline Mouse $M y c$ & None & Tet-on & No & $\begin{array}{c}3 \text { wpi: } 30 \% \text { HA, } 70 \% \text { HP } \\
16 \text { wpi: } 7 \text { out of } 8 \text { showed HA, } \\
1 \text { showed HCC }\end{array}$ & [47] \\
\hline Zebrafish $m y c a$ and $m y c b$ & Ac/Ds & LexPR & No & $\begin{array}{l}\text { Liver tumour progression from } \\
\text { HP, HA to multinodular HCC }\end{array}$ & [53] \\
\hline $\operatorname{tg} f \beta 1 a$ & $\mathrm{Ac} / \mathrm{Ds}$ & LexPR & No & $\begin{array}{c}6 \text { wpi: } 30 \% \text { mixed HCC + CCA, } \\
20 \% \mathrm{HCC}+\mathrm{BHP}, 10 \% \mathrm{HCC} \\
20 \% \mathrm{HA}, 20 \% \mathrm{HP}+\mathrm{BHP}\end{array}$ & [55] \\
\hline Twist1a-ER $R^{T 2} / x m r k$ & Ac/Ds & Tet-on & No & $\begin{array}{l}8 \mathrm{dpi}: 46 \% \text { showed distant } \\
\text { dissemination of tumour cells, } \\
39 \% \text { showed abdominal } \\
\text { dissemination and the rest } \\
\text { showed no dissemination }\end{array}$ & [57] \\
\hline
\end{tabular}

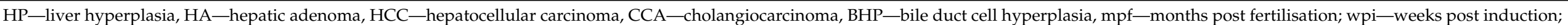

dpi-days post induction; mpi-months post induction. * Transgenic lines showed dosage- and time-dependent tumour incidence and severity. 
Molecularly, liver tumours from several of our transgenic models have been subjected to transcriptomic analyses and cross species comparison. In the microarray analysis of our first non-inducible ras $^{V 12}$ model, we observed the activation of several important signalling pathways that are also seen in human liver hyperplasia and HCC. Cross-species analysis also showed that upregulated zebrafish hyperplastic liver-enriched genes and HCC-enriched genes were significantly associated with human dysplastic liver and HCC respectively. A few genes from the gene signatures that the analyses surfaced had also been reported as prognostic markers in human HCC [34]. RNA-sequencing and cross species analyses of HCC samples from $x m r k$ fish showed a significant resemblance to human HCC S2 subtype that was categorised by a meta-analysis of nine patient cohorts across the globe [63]. Myc and its co-activator MAX were among the top 10 most dysregulated transcription factors in the $x m r k$ liver, further validating this model as the S2 subtype is also characterised by the activation of a Myc signature [64]. For the Myc transgenic model, cross-species transcriptome analyses revealed the highest correlation to Myc transgenic mouse compared to other mice models of HCC. The zebrafish tumours also showed significant similarity with human HCC as compared to lower-grade tumours-a result that was consistent even when two different human HCC datasets were used. Moreover, 16 Myc target genes, retrieved from the Molecular Signatures Database [65], were found to be amongst the upregulated genes from the zebrafish Myc tumours. The 16-gene signature was able to predict Myc transgenic mice and differentiate between lower and higher-grade human liver cancers [47]. Taken together, these findings strongly suggest the conservation of molecular pathways in Myc-induced liver tumours across the three species. In a transcriptome study of all three transgenic liver tumours, induced by kras ${ }^{V 12}, x m r k$ and $M y c$, all three types apparently showed the highest similarity with very advanced human HCC as compared to various human liver disease conditions from cirrhotic nodules to various grades of HCC [66]. Moreover, the common up- and down-regulated genes found from these three zebrafish tumour models also showed the same up- and down-regulation in human HCC, suggesting the conservation of fundamental genes necessary for neoplasia.

Along with studying the histology and transcriptome of liver tumours, we also investigated the dysregulation of multiple signalling pathways that have been implicated in oncogene-signalling and tumorigenesis. In $\mathrm{kras}^{\mathrm{V} 12}$-expressing liver tumours, progressively increasing activation of MAPK and Wnt/ $\beta$-catenin signalling pathways was observed from benign to malignant tumours [34,56]; inhibition of Wnt-signalling also reduced oncogenic liver size in Myc fish [67]. These two pathways are prominently activated in human liver cancer [68-70]. The loss of p53 function in human liver cancer is one of the most frequent mutations [71,72] and shows poor prognosis [73]; its loss in kras V12 and zebrafish myca lines also results in accelerated tumour progression and mortality rates $[34,54]$. Inhibition of the VEGF/FGF pathway suppressed liver enlargement in induced $\mathrm{kras}^{\mathrm{V} 12}$ and Myc fish, implicating that VEGF/FGF signalling and angiogenesis is necessary for oncogenic liver tumour development in zebrafish [67]. Hypervascularity is not only commonly found in human HCC, but many treatments for advanced HCC also target angiogenesis, such as the well-known multikinase inhibitor, sorafenib, which inhibits angiogenesis via the VEGF pathway [74,75]. The crossing of our Myc and xmrk lines resulted in quicker and more severe liver carcinogenesis than Myc or $x m r k$ single transgenic fish. Interestingly, the Warburg effect, or aerobic glycolysis, is potentially at play in double transgenic tumours. The $M y c / x m r k$ tumours might have a preference for acquiring energy via glycolytic pathways as transcriptome analysis revealed a downregulation of fatty acid and amino acid metabolism genes and upregulation of critical glycolytic genes such as $p k m 2$ [62], one of the rate-limiting enzymes in aerobic glycolysis [76]. These characteristics are also seen in transcriptomic and metabolomic studies on human HCC [77-79]. These dysregulated molecular pathways and their outcomes seen in the induced zebrafish liver tumours are also observed in human liver cancer, implying that liver tumour events in zebrafish likely occur via similar pathways as those in humans. 


\section{Important Findings from Our Models}

\subsection{Oncogene Addiction: Tumour Regression and Re-Induction}

Spontaneous regression of tumours is rare in humans, and is usually associated with the stimulation of the immune system of cancer patients [80]. One of the most intriguing observations from our inducible transgenic zebrafish models is that the induced tumours show the ability to regress when the oncogene is no longer expressed by the withdrawal of the chemical inducer. The tumours can be re-induced by exposing the fish to the inducer again to re-activate oncogene expression. Since our models show that the expression of a single oncogene is sufficient to induce liver tumours and HCC, these observations altogether indicate the presence of an oncogene addiction phenomenon, where cancer initiation and maintenance is dependent on a single or a few oncogenes [81]. The regressed tumours in our models shrink in size and revert to normal liver histology $[43,46,54]$. Transcriptomic analysis also revealed a reversal of molecular changes in regressing tumours compared to tumours with progressing HCC [64].

There are two possible mechanisms of tumour regression: (1) tumour hepatocytes undergo cell death and are eliminated while normal hepatocytes eventually replace these tumour hepatocytes via proliferation and differentiation, and (2) tumour hepatocytes might be directly reverted to normal hepatocytes. In order to test the two possibilities, we developed a CreER transgenic line that allowed us to trace liver cell lineage (Figure 1F) [82]. In this transgenic line, tamoxifen-activated Cre protein, $\mathrm{CreER}^{\mathrm{T} 2}$, is expressed only in the presence of doxycycline. It also includes liver-specific promoter-controlled EGFP flanked by loxP sequences, and a DsRed gene at the end. When crossed with the xmrk line, the double transgenic CreER/xmrk fish express EGFP in all hepatocytes, which start to express $x m r k$ and progress into liver tumours upon doxycycline induction. The addition of tamoxifen initiates Cre/loxP recombination where existing tumour hepatocytes begin to permanently express DsRed instead of EGFP. This allowed for the distinction between DsRed-expressing hepatocytes from tumour-cell lineage and newly differentiated EGFP-expressing hepatocytes after tamoxifen is removed. Upon initiation of tumour regression by cessation of doxycycline treatment, we observed a large increase in apoptosis and a decrease in proliferation of liver tumours within the first week. After four weeks of tumour regression, we observed both DsRed- and EGFP-expressing hepatocytes in normal liver. Histological and transcriptomic analyses confirmed that both populations of hepatocytes are normal when compared to wildtype control hepatocytes. Hence, our studies demonstrated the possibility of reversion of tumour cells to normal cells by suppression of the major addictive oncogene or oncogenic pathway [82].

\subsection{Immune Response and Inflammation}

It is known that a wide range of innate and adaptive immune responses are involved in the development and progression of human liver cancer, having both tumour-promoting and anti-tumour capabilities [83-85]. Investigation into the microenvironment of the induced liver tumours has shown that the immune system is very much involved in zebrafish liver cancer as well.

It is clear that neutrophils and macrophages play a tumorigenic role in our transgenic zebrafish models. With the help of fluorescence-labelled neutrophils and macrophages in several transgenic zebrafish strains $[86,87]$, we were able to study innate immune cell infiltration and localisation as well as their involvement in liver tumour initiation and progression. Neutrophils are rapidly recruited to the $\mathrm{kras}^{\mathrm{V}}{ }^{2}$ larvae liver upon induction, with a significant increase in neutrophil density in the liver from 8-16 hours post-induction (hpi) onwards $[88,89]$. Time-lapse confocal microscopy revealed that neutrophils move actively around the $\mathrm{Kras}^{\mathrm{V} 12}$ liver but remain relatively stationary after infiltration, in contrast to the control liver, where neutrophils were equally active regardless of location. kras $^{V 12}$ liver only became significantly enlarged from $24 \mathrm{hpi}$, suggesting the tumorigenic function of neutrophils in the liver $[88,89]$. An increase in tumour-associated neutrophils (TANs) after oncogene induction was also seen in Myc fish [90], and both neutrophil and macrophage 
numbers in the liver increased upon xmrk induction [64]. The inhibition of neutrophils and macrophages was able to attenuate tumour growth in $\mathrm{kras}^{\mathrm{V12}}$ larvae [59], while neutrophil depletion and inhibition of neutrophil differentiation in Myc fish also suppressed tumour growth [90]. These observations indicate that neutrophils and macrophages have pro-tumour functions in tumorigenesis, but their involvement in HCC regression has likewise been noted. Like in the HCC liver, TAN and tumour-associated macrophage (TAM) numbers are increased in the early and late regressing $x m r k$ tumours. The immune cells seem to be clustered regionally, with TAMs clearly clustering around blood vessels, compared to their uniform distribution in the HCC liver. Neutrophils and macrophages likely have different functions in tumorigenesis and tumour regression [64].

How neutrophils and macrophages are involved in zebrafish liver cancer is complex due to crosstalk in the tumour microenvironment. Cause-and-effect relationships are not only one-way, but might be bi-directional, suggesting the presence of feedback loops. On one hand, angiogenesis seems to aid neutrophil recruitment to the hepatic Myc tumour and tumorigenesis as inhibition of angiogenesis decreases TAN numbers and tumour growth [90]. On the other hand, a decrease in TANs lowers tumour-blood vessel density [91]. Neutrophils and macrophages were also found to contribute to hepatic stellate cell (HSC) activation, with macrophages also supporting HSC survival. HSCs in turn secrete Tgf $\beta 1$ which promotes TAN and TAM tumorigenic function [89].

Further investigation suggests that certain inflammatory cytokines also contribute to hepatocarcinogenesis either directly or by inducing immune cells. kras ${ }^{V 12}$ hepatocytes increase expression of $\operatorname{tg} f \beta 1 a$, likely recruiting and inducing neutrophils, which promote a pro-inflammatory tumorigenic microenvironment. Tgf- $\beta$ depletion and inhibition decreased liver size and neutrophil density, and partially rescued TAN anti-tumour cytokine expression [88]. This has been further confirmed in another study where tgf- $\beta$ signalling inhibition also reduced liver size and downregulated expression of pro-tumour genes in hepatocytes, TANs and TAMs [89]. In our liver-specific tof $\beta 1 a$ model, tgf $\beta 1 a$ overexpression progressively induced liver inflammation during tumour initiation [92]. An investigation into cholangiocyte involvement in HCC indicated that il17a/f1 expression was significantly upregulated and secreted by cholangiocytes, in turn directly augmenting kras ${ }^{V 12}$ liver carcinogenesis. Il17a/f1 inhibition reduced liver growth and TAN and TAM numbers [93].

\subsection{Sex Disparity and Hormones}

Gender disparity in human primary liver cancer has been well-documented, with liver cancer being 2 to 4 times more prevalent in males than in females [94,95]. Differential gene expression and pathway activation between the two sexes has been observed in human patients [96]. Likewise, this phenomenon has also been observed in our transgenic zebrafish models and has been investigated to further elucidate mechanisms in HCCrelated sex disparity.

HCC develops and progresses faster in male $\mathrm{kras}^{\mathrm{V} 12}$ fish than in female kras ${ }^{V 12}$ fish [59,60]. After 10 days of doxycycline induction, all male liver tumours showed HCC, with $80 \%$ at an advanced stage, while only $70 \%$ of females had early HCC. Male tumours were also more severe after long-term induction, exhibiting higher proliferation, $\mathrm{Wnt} / \beta$ catenin pathway activation, and loss of E-cadherin, an important tumour-suppressing molecule. Male tumours advanced to have multiple nodules suggestive of different tumour colonies, while their female counterparts remained homogenous. Complete regression of male tumours also took a longer time [60]. The male-bias phenomenon is also seen in $x m r k$, Myc, and Myc/xmrk transgenic fish [61,97]. Xmrk and myc/xmrk males developed higher grade HCC quicker than females and male tumours from all three lines showed a higher rate of proliferation. Myc/xmrk double transgenic tumour regression was also delayed in male fish.

Sex hormones have been found to contribute to the processes of hepatic tumorigenesis and tumour regression in zebrafish. Androgen treatment in both male and female $\mathrm{kras}^{\mathrm{V} 12}$ fish stimulated cell proliferation in the liver tumour, accelerating tumour growth and 
progression. The opposite was seen in estrogen-treated fish [60]. Similar observations were made in Myc/xmrk fish, where androgen-treated females developed HCC faster and regressed slower than their doxycycline-only controls, while estrogen-treated males showed opposite effects [97]. To further investigate the role of androgen in HCC, or more specifically, androgen-receptor signalling, a liver-specific androgen receptor knockout line (L-ARKO) was developed, validated, and crossed with the $\mathrm{kras}^{\mathrm{V} 12}$ line. The absence of androgen receptors indeed attenuated tumour development and cell proliferation during early tumorigenesis. Interestingly, all fish went on to develop HCC, indicating that the tumorigenic role of androgen-receptor signalling is restricted to the early stages of tumour development [98].

Male and female fish show differences in tumour microenvironment as well. Male kras $^{V 12}$, xmrk, and Myc tumours recruit more neutrophils and macrophages than corresponding female tumours [54,59], an observation confirmed in human pre-HCC and HCC samples [59]. TANs and TAMs from males also show greater pro-tumour gene expression than immune cells from the female tumour. Cortisol, an adrenal hormone, was more robustly produced in the male liver and contributed to the increased production of $\operatorname{tgf} \beta 1$ [59], which has been mentioned earlier to possess pro-tumour functions in tumorigenesis. In another study, it was found that serotonin expression and production was higher in the kras $^{V 12}$ male tumour, enhancing HSC numbers and activation. The stimulated HSCs then contribute to the increase in $\operatorname{tgf} \beta 1$ production [61]. Higher serotonin levels, tgf $\beta 1$ production, and HSC numbers were also observed in xmrk and Myc male tumours [54]. More importantly, increases in cortisol, serotonin and $\operatorname{tgf} \beta 1$ levels have been verified in human samples $[61,90]$. It is interesting to note that some non-sex hormones such as cortisol and serotonin are also involved in sex disparity of liver tumour formation.

The key pathways and mechanisms involved in tumour development and regression are summarised and illustrated in Figure 2.

\subsection{Muscle-Wasting and Cancer Cachexia}

Cancer-associated cachexia is a syndrome whose main symptoms are the loss of skeletal muscle mass and adipose tissue, amongst others. Though mechanisms and mediators of cancer cachexia have surfaced in the past few years, there is currently still no effective medical treatment for cachexia [99,100]. In the treatment of human cancers, although nutritional interventions had no impact on survival rates [101], starvation therapy has been proposed as a novel treatment that could also improve response to current therapies [102,103]. To further investigate muscle-wasting accompanied with cancer progression, the zebrafish model could be an excellent experimental system for mechanistic investigation as the nutrition effect can be easily manipulated and investigated in this model organism.

Examination of our induced kras ${ }^{V 12}$ fish indeed revealed progressive wasting of the skeletal muscles [104]. Fish body weight and muscle fibres decreased significantly as doxycycline treatment progressed. Underfeeding was able to slow down carcinogenesis but the rate of muscle-wasting was increased due to insufficient nutrition. However, overfeeding led to both faster carcinogenesis and faster muscle-wasting, which was more severe than the muscle-wasting seen in underfed fish, strongly suggesting that HCC was heavily involved in the muscle-wasting phenomenon. Leptin, a hormone that regulates energy homeostasis [105], was identified to be involved in HCC-induced muscle-wasting as well as in human liver disease. Expression of leptin was significantly increased in $\mathrm{kras}^{V 12}$ livers compared to wildtype control fish, an increase that was further exacerbated by overfeeding. Human liver samples also displayed a significant increase in leptin expression as liver disease progressed, which was the highest in HCC samples. To investigate the role of leptin in HCC-induced muscle-wasting, a leptin-receptor (Lepr) knockout line was generated and crossed with rras $^{V 12}$ fish. After tumour induction, Lepr mutant kras $^{V 12}$ fish had better survival rates and significantly reduced muscle-wasting in all differentially fed groups, though carcinogenesis remained unaffected. Treatment of Lepr mutant kras ${ }^{V 12}$ fish with a myostatin inhibitor further reduced muscle-wasting and loss of body weight. 
These observations show that leptin signalling indeed plays a critical role in HCC-induced muscle-wasting and a combination of leptin signalling and myostatin inhibition might prove to be an effective treatment strategy for cancer cachexia patients [106].

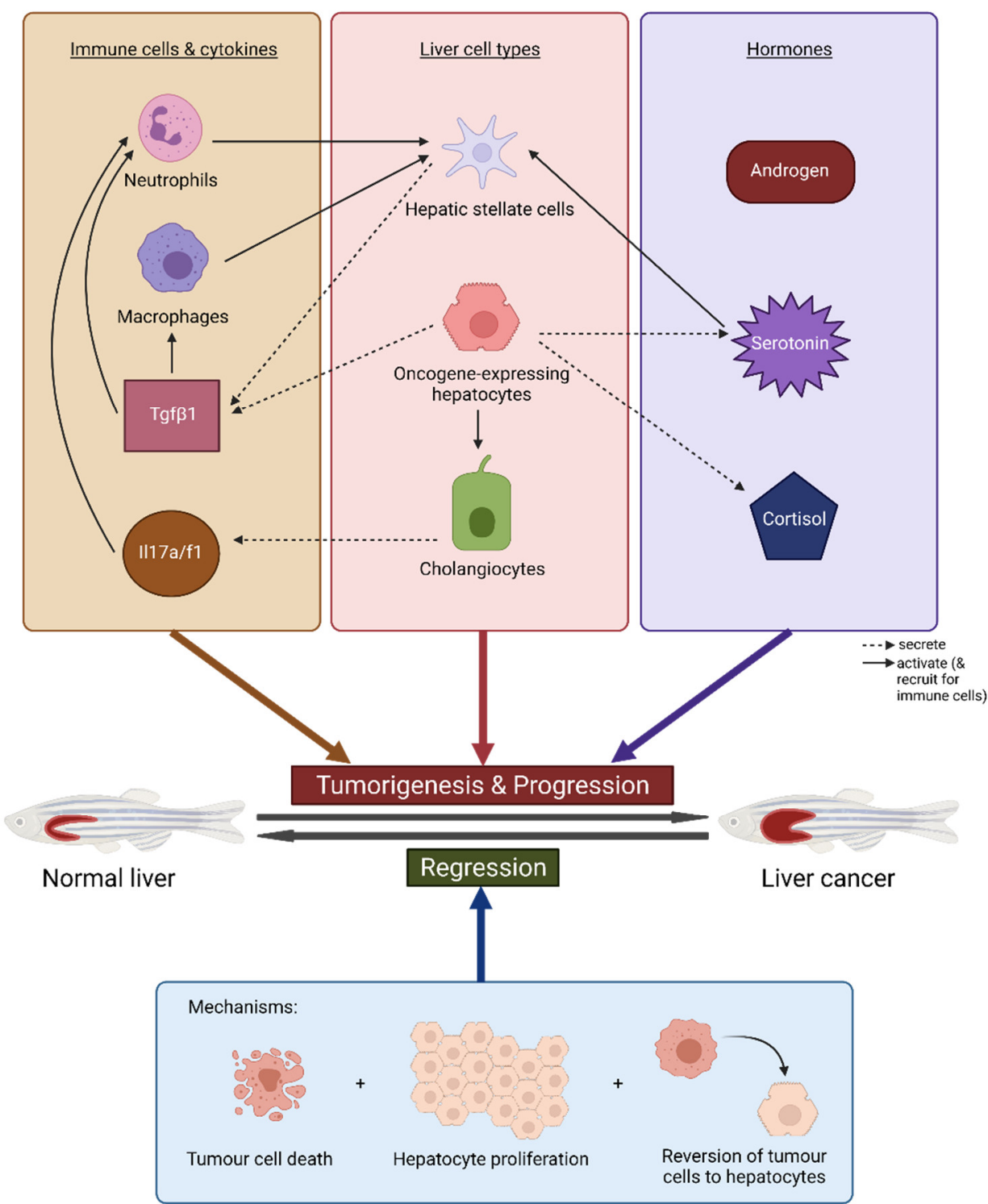

Figure 2. Summary of key pathways and mechanisms involved in tumour development and regression in our transgenic zebrafish models of liver cancer. The figure displays the main liver cells (hepatocytes and cholangiocytes) and immune cell types, cytokines and hormones that contribute to or exacerbate tumorigenesis and progression to liver cancer, and the crosstalk between them. The three mechanisms for tumour regression are also shown. Figure created with BioRender.com (accessed on 17 August 2021).

\subsection{Chemical and Toxicological Screening Using Zebrafish HCC Models}

A huge advantage that the zebrafish model has over rodents is the ability to do highthroughput in vivo chemical screening, such as for novel drug discovery or preclinical drug screening $[106,107]$. To explore the feasibility of using our oncogene transgenic zebrafish larvae for potential chemical screens, we treated kras ${ }^{V 12}$ larvae with known pathway inhibitors and were able to grade drug efficacy according to liver sizes following treatment with different chemicals [43]. Results indicated that ERK and AKT pathways both need to be inhibited for the total suppression of tumorigenesis. Since the liver is labeled by fluorescent protein expression in most of our oncogene transgenic zebrafish 
models, we further refined the protocol by quantitative measurement of 2D liver size in zebrafish larvae using online available ImageJ software and this might be developed into a potentially high-throughput and automated chemical screening platform $[67,108]$. We also used Twist $1 a-E R^{T 2} / x m r k$ fish to carry out a small scale chemical screening for anti-metastasis drugs. We started with 67 FDA-approved drugs and found 3 known human drugs that were able to reduce the frequency of fish with dissemination and migration of tumour cells from the liver. Further validation analyses identified adrenosterone as the drug that could suppress the dissemination of highly metastatic human cancer cell lines in zebrafish xenotransplants by inhibition of the novel target, HSD11ß1 [57].

Though the drugs for cancer treatment identified in chemical screens using our zebrafish models have yet to be tested in clinical trials, many other laboratories have found some potential drug compounds based on zebrafish screens and several of these compounds have already entered clinical trials $[109,110]$. For example, North et al. performed a chemical screen in zebrafish and identified prostaglandin $\mathrm{E}_{2}\left(\mathrm{PGE}_{2}\right)$ to be capable of stimulating haematopoietic stem cells (HSCs) [111]; 16,16-dimethyl-PGE 2 (dmPGE 2 ), a stable derivative of $\mathrm{PGE}_{2}$, showed the ability to enhance HSC proliferation, survival, and homing to bone marrow, as well as long-term stable engraftment in transplantation models [112]. The compound subsequently entered phase I clinical trials for use in umbilical cord blood (UCB) treatment for transplantation in leukemic patients, who were co-transplanted with one treated UCB and one untreated UCB. Results showed sustained engraftment and long-term hematopoiesis as a result of the $\mathrm{dmPGE}_{2}$-treated UCB unit in the majority of patients [113]. A phase II trial also revealed a lower incidence rate of graft vs. host disease [109]. Mandelbaum et al. have developed a cultured zebrafish pluripotent blastomere system to screen for inhibitors of the $M Y B$ gene, which is overexpressed in adenoid cystic carcinoma (ACC). A retinoic acid agonist, all-trans retinoic acid (ATRA), was found to decrease gene expression in the zebrafish blastomeres and could suppress tumour growth in patient-derived xenograft models [114]. Early reports on an ongoing phase II clinical trial of ATRA suggest stabilisation in advanced ACC patients [110].

Besides being utilised for drug screening, the oncogene transgenic zebrafish model could also be used to screen and assess how various chemicals affect tumorigenesis. This approach is particularly valuable to test environmental toxicants for their potential impact in inducing or promoting carcinogenesis. We have tested the $\mathrm{kras}^{V 12}$ fish with several different categories of environmental toxicants such as heavy metals and organic toxicants for their effects on inflammation and liver tumorigenesis based on neutrophil count and liver size respectively. Increases in inflammation were accompanied by corresponding increases in tumorigenesis, once again showing the important role inflammation plays in tumour formation [115]. The kras V12 fish model including adult fish has also been used by other laboratories to evaluate the effects of environmental toxicants, tris(1,3-dichloro-2propyl) phosphate (TDCIPP) and perfluorooctane sulfonate (PFOS). Exposure to these two chemicals caused more severe HCC and increased HCC frequency, respectively [116-118].

\section{Concluding Remarks}

As global liver cancer prevalence continues to increase and treatment response remains poor, the development of new and improved therapies is highly desired. Over the past decade, our lab has developed several conditional transgenic systems and established chemically inducible transgenic zebrafish lines that have shown to be robust models of HCC and its related processes such as metastasis and muscle-wasting. Using these models, we have elucidated various molecular insights into the different mechanisms involved in liver cancer initiation, progression and regression. Chemical screening using the fish has also revealed novel anti-metastatic drugs as well as the inflammatory and carcinogenic ability of certain environmental toxicants. These observations and findings provide potential options to consider in the discovery and development of new therapies to treat liver cancer. Furthermore, our successful strategies may also be applicable for the development of cancer models in other organs/tissues. 
So far, cancer cachexia studies in fish is only limited to muscle wasting. In human cancer patients, cachexia can also present with adipose tissue-wasting, inflammation and alterations in smell and taste and gastrointestinal tract hormone levels [119]. A rat HCC model presenting weight and skeletal muscle loss also showed a progressive decline in cardiac muscle mass and cardiac function [120]. Future works can focus on the characterisation of HCC's effects on other organs in fish, which could further allow for the screening of more treatment options.

In a study, we also demonstrated the feasibility for transformed cancer cells to be reverted to normal cells after the suppression of expression of the addicted oncogene. This observation provides a therapeutic basis for using a chemical drug to target the addicted oncogene. We also observed that cancer-reverted cells were more susceptible to re-induction of carcinogenesis and thus our model may also provide a model to investigate cancer dormancy and recurrence. We have used a transgenic recombination approach to trace cancer cell lineage during tumour regression, a more powerful multi-color lineage tracing approach followed by single cell RNA-seq technology could be further applied to identify potentially different classes of cancer-reverted cells.

The development of early diagnosis markers for HCC has been of high importance, as patients are usually diagnosed at advanced stages and the well-studied serum marker $\alpha$-fetoprotein has limited sensitivity and specificity. With the chemically-inducible liver tumour models, we are able to study tumour initiation and progression at different stages. Making use of proteomic and metabolomic approaches, our transgenic models could be used to explore new serological biomarkers for HCC. Since the zebrafish liver tumour models also displayed gender disparity, biomarker exploration can be performed in a gender-specific manner.

Author Contributions: A.Q.L. and Z.G. wrote the manuscript. A.Q.L., Y.L. and Z.G. conceptualised the manuscript. All authors have read and agreed to the published version of the manuscript.

Funding: This research was funded by Ministry of Education, Singapore, grant numbers, R154000B70114 and R154000B88112.

Conflicts of Interest: The authors declare no conflict of interest.

\section{References}

1. Sung, H.; Ferlay, J.; Siegel, R.L.; Laversanne, M.; Soerjomataram, I.; Jemal, A.; Bray, F. Global Cancer Statistics 2020: GLOBOCAN Estimates of Incidence and Mortality Worldwide for 36 Cancers in 185 Countries. CA Cancer J. Clin. 2021, 71, 209-249. [CrossRef]

2. Liu, Z.; Jiang, Y.; Yuan, H.; Fang, Q.; Cai, N.; Suo, C.; Jin, L.; Zhang, T.; Chen, X. The trends in incidence of primary liver cancer caused by specific etiologies: Results from the Global Burden of Disease Study 2016 and implications for liver cancer prevention. J. Hepatol. 2019, 70, 674-683. [CrossRef]

3. Marin, J.J.G.; Briz, O.; Herraez, E.; Lozano, E.; Asensio, M.; Di Giacomo, S.; Romero, M.R.; Osorio-Padilla, L.M.; Santos-Llamas, A.I.; Serrano, M.A.; et al. Molecular bases of the poor response of liver cancer to chemotherapy. Clin. Res. Hepatol. Gastroenterol. 2018, 42, 182-192. [CrossRef]

4. Ko, K.L.; Mak, L.Y.; Cheung, K.S.; Yuen, M.F. Hepatocellular carcinoma: Recent advances and emerging medical therapies. F1000Research 2020, 9. [CrossRef] [PubMed]

5. Recio-Boiles, A.; Babiker, H.M. Liver Cancer; StatPearls Publishing LLC: Treasure Island, FL, USA, 2021.

6. Eisen, J.S. History of Zebrafish Research. In The Zebrafish in Biomedical Research; Cartner, S.C., Eisen, J.S., Farmer, S.C., Guillemin, K.J., Kent, M.L., Sanders, G.E., Eds.; Academic Press: Cambridge, MA, USA, 2020; pp. 3-14.

7. Thisse, C.; Thisse, B. High-resolution in situ hybridization to whole-mount zebrafish embryos. Nat. Protoc. 2008, 3, 59-69. [CrossRef] [PubMed]

8. Rafferty, S.A.; Quinn, T.A. A beginner's guide to understanding and implementing the genetic modification of zebrafish. Prog. Biophys. Mol. Biol. 2018, 138, 3-19. [CrossRef] [PubMed]

9. Liu, S.; Leach, S.D. Zebrafish models for cancer. Annu. Rev. Pathol. 2011, 6, 71-93. [CrossRef]

10. McConnell, A.M.; Noonan, H.R.; Zon, L.I. Reeling in the Zebrafish Cancer Models. Annu. Rev. Cancer Biol. 2021, 5, 331-350. [CrossRef]

11. Barbazuk, W.B.; Korf, I.; Kadavi, C.; Heyen, J.; Tate, S.; Wun, E.; Bedell, J.A.; McPherson, J.D.; Johnson, S.L. The syntenic relationship of the zebrafish and human genomes. Genome Res. 2000, 10, 1351-1358. [CrossRef]

12. Howe, K.; Clark, M.D.; Torroja, C.F.; Torrance, J.; Berthelot, C.; Muffato, M.; Collins, J.E.; Humphray, S.; McLaren, K.; Matthews, L.; et al. The zebrafish reference genome sequence and its relationship to the human genome. Nature 2013, 496, 498-503. [CrossRef] 
13. Xu, C.; Zon, L.I. The zebrafish as a model for human disease. In Fish Physiology; Perry, S.F., Ekker, M., Farrell, A.P., Brauner, C.J., Eds.; Academic Press: Cambridge, MA, USA, 2010; Volume 29, pp. 345-365.

14. Goldsmith, J.R.; Jobin, C. Think Small: Zebrafish as a Model System of Human Pathology. J. Biomed. Biotechnol. 2012, $2012,1-12$. [CrossRef]

15. Santoriello, C.; Zon, L.I. Hooked! Modeling human disease in zebrafish. J. Clin. Investig. 2012, 122, 2337-2343. [CrossRef] [PubMed]

16. Bradford, Y.M.; Toro, S.; Ramachandran, S.; Ruzicka, L.; Howe, D.G.; Eagle, A.; Kalita, P.; Martin, R.; Taylor Moxon, S.A.; Schaper, K.; et al. Zebrafish Models of Human Disease: Gaining Insight into Human Disease at ZFIN. ILAR J. 2017, 58, 4-16. [CrossRef] [PubMed]

17. Evason, K.J.; Francisco, M.T.; Juric, V.; Balakrishnan, S.; Lopez Pazmino Mdel, P.; Gordan, J.D.; Kakar, S.; Spitsbergen, J.; Goga, A.; Stainier, D.Y. Identification of Chemical Inhibitors of beta-Catenin-Driven Liver Tumorigenesis in Zebrafish. PLoS Genet. 2015, 11, e1005305. [CrossRef]

18. Lu, J.W.; Liao, C.Y.; Yang, W.Y.; Lin, Y.M.; Jin, S.L.; Wang, H.D.; Yuh, C.H. Overexpression of endothelin 1 triggers hepatocarcinogenesis in zebrafish and promotes cell proliferation and migration through the AKT pathway. PLoS ONE 2014, 9, e85318. [CrossRef]

19. Mudbhary, R.; Hoshida, Y.; Chernyavskaya, Y.; Jacob, V.; Villanueva, A.; Fiel, M.I.; Chen, X.; Kojima, K.; Thung, S.; Bronson, R.T.; et al. UHRF1 overexpression drives DNA hypomethylation and hepatocellular carcinoma. Cancer Cell 2014, 25, 196-209. [CrossRef] [PubMed]

20. Lu, J.W.; Yang, W.Y.; Tsai, S.M.; Lin, Y.M.; Chang, P.H.; Chen, J.R.; Wang, H.D.; Wu, J.L.; Jin, S.L.; Yuh, C.H. Liver-specific expressions of HBx and src in the p53 mutant trigger hepatocarcinogenesis in zebrafish. PLoS ONE 2013, 8, e76951. [CrossRef]

21. Rekha, R.D.; Amali, A.A.; Her, G.M.; Yeh, Y.H.; Gong, H.Y.; Hu, S.Y.; Lin, G.H.; Wu, J.L. Thioacetamide accelerates steatohepatitis, cirrhosis and HCC by expressing HCV core protein in transgenic zebrafish Danio rerio. Toxicology 2008, 243, 11-22. [CrossRef]

22. Mizgirev, I.; Revskoy, S. Generation of clonal zebrafish lines and transplantable hepatic tumors. Nat. Protoc. 2010, 5, 383-394. [CrossRef]

23. Avci, M.E.; Keskus, A.G.; Targen, S.; Isilak, M.E.; Ozturk, M.; Atalay, R.C.; Adams, M.M.; Konu, O. Development of a novel zebrafish xenograft model in ache mutants using liver cancer cell lines. Sci. Rep. 2018, 8, 1570. [CrossRef]

24. Khan, N.; Mahajan, N.K.; Sinha, P.; Jayandharan, G.R. An efficient method to generate xenograft tumor models of acute myeloid leukemia and hepatocellular carcinoma in adult zebrafish. Blood Cells Mol. Dis. 2019, 75, 48-55. [CrossRef] [PubMed]

25. Wrighton, P.J.; Oderberg, I.M.; Goessling, W. There Is Something Fishy About Liver Cancer: Zebrafish Models of Hepatocellular Carcinoma. Cell. Mol. Gastroenterol. Hepatol. 2019, 8, 347-363. [CrossRef] [PubMed]

26. Nakayama, J.; Gong, Z. Transgenic zebrafish for modeling hepatocellular carcinoma. MedComm 2020, 1, 140-156. [CrossRef]

27. Li, X.; Benjamin, I.S.; Alexander, B. Reproducible production of thioacetamide-induced macronodular cirrhosis in the rat with no mortality. J. Hepatol. 2002, 36, 488-493. [CrossRef]

28. Groos, J.; Bannasch, P.; Schwarz, M.; Kopp-Schneider, A. Comparison of mode of action of four hepatocarcinogens: A model-based approach. Toxicol. Sci. 2007, 99, 446-454. [CrossRef]

29. Spitsbergen, J.M.; Tsai, H.W.; Reddy, A.; Miller, T.; Arbogast, D.; Hendricks, J.D.; Bailey, G.S. Neoplasia in zebrafish (Danio rerio) treated with N-methyl-N'-nitro-N-nitrosoguanidine by three exposure routes at different developmental stages. Toxicol. Pathol. 2000, 28, 716-725. [CrossRef]

30. Spitsbergen, J.M.; Tsai, H.W.; Reddy, A.; Miller, T.; Arbogast, D.; Hendricks, J.D.; Bailey, G.S. Neoplasia in zebrafish (Danio rerio) treated with 7,12-dimethylbenz[a]anthracene by two exposure routes at different developmental stages. Toxicol. Pathol. 2000, 28, 705-715. [CrossRef]

31. Mizgireuv, I.V.; Majorova, I.G.; Gorodinskaya, V.M.; Khudoley, V.V.; Revskoy, S.Y. Carcinogenic effect of N-nitrosodimethylamine on diploid and triploid zebrafish (Danio rerio). Toxicol. Pathol. 2004, 32, 514-518. [CrossRef]

32. Lam, S.H.; Wu, Y.L.; Vega, V.B.; Miller, L.D.; Spitsbergen, J.; Tong, Y.; Zhan, H.; Govindarajan, K.R.; Lee, S.; Mathavan, S.; et al. Conservation of gene expression signatures between zebrafish and human liver tumors and tumor progression. Nat. Biotechnol. 2006, 24, 73-75. [CrossRef]

33. Lam, S.H.; Gong, Z. Modeling Liver Cancer Using Zebrafish: A Comparative Oncogenomics Approach. Cell Cycle 2006, 5, 573-577. [CrossRef]

34. Nguyen, A.T.; Emelyanov, A.; Koh, C.H.; Spitsbergen, J.M.; Lam, S.H.; Mathavan, S.; Parinov, S.; Gong, Z. A high level of liver-specific expression of oncogenic Kras(V12) drives robust liver tumorigenesis in transgenic zebrafish. Dis. Model. Mech. 2011, 4, 801-813. [CrossRef] [PubMed]

35. Arrington, A.K.; Heinrich, E.L.; Lee, W.; Duldulao, M.; Patel, S.; Sanchez, J.; Garcia-Aguilar, J.; Kim, J. Prognostic and predictive roles of KRAS mutation in colorectal cancer. Int. J. Mol. Sci. 2012, 13, 12153-12168. [CrossRef]

36. Valtorta, E.; Misale, S.; Sartore-Bianchi, A.; Nagtegaal, I.D.; Paraf, F.; Lauricella, C.; Dimartino, V.; Hobor, S.; Jacobs, B.; Ercolani, C.; et al. KRAS gene amplification in colorectal cancer and impact on response to EGFR-targeted therapy. Int. J. Cancer 2013, 133, 1259-1265. [CrossRef] [PubMed]

37. Favazza, L.A.; Parseghian, C.M.; Kaya, C.; Nikiforova, M.N.; Roy, S.; Wald, A.I.; Landau, M.S.; Proksell, S.S.; Dueker, J.M.; Johnston, E.R.; et al. KRAS amplification in metastatic colon cancer is associated with a history of inflammatory bowel disease and may confer resistance to anti-EGFR therapy. Mod. Pathol. 2020, 33, 1832-1843. [CrossRef] [PubMed] 
38. Karachaliou, N.; Mayo, C.; Costa, C.; Magri, I.; Gimenez-Capitan, A.; Molina-Vila, M.A.; Rosell, R. KRAS mutations in lung cancer. Clin. Lung Cancer 2013, 14, 205-214. [CrossRef]

39. Wagner, P.L.; Perner, S.; Rickman, D.S.; LaFargue, C.J.; Kitabayashi, N.; Johnstone, S.F.; Weir, B.A.; Meyerson, M.; Altorki, N.K.; Rubin, M.A. In situ evidence of KRAS amplification and association with increased p21 levels in non-small cell lung carcinoma. Am. J. Clin. Pathol. 2009, 132, 500-505. [CrossRef]

40. Wagner, P.L.; Stiedl, A.C.; Wilbertz, T.; Petersen, K.; Scheble, V.; Menon, R.; Reischl, M.; Mikut, R.; Rubin, M.A.; Fend, F.; et al. Frequency and clinicopathologic correlates of KRAS amplification in non-small cell lung carcinoma. Lung Cancer 2011, 74, 118-123. [CrossRef]

41. Delire, B.; Starkel, P. The Ras/MAPK pathway and hepatocarcinoma: Pathogenesis and therapeutic implications. Eur. J. Clin. Investig. 2015, 45, 609-623. [CrossRef]

42. Emelyanov, A.; Parinov, S. Mifepristone-inducible LexPR system to drive and control gene expression in transgenic zebrafish. Dev. Biol. 2008, 320, 113-121. [CrossRef]

43. Nguyen, A.T.; Emelyanov, A.; Koh, C.H.; Spitsbergen, J.M.; Parinov, S.; Gong, Z. An inducible kras(V12) transgenic zebrafish model for liver tumorigenesis and chemical drug screening. Dis. Models Mech. 2012, 5, 63-72. [CrossRef]

44. Loew, R.; Heinz, N.; Hampf, M.; Bujard, H.; Gossen, M. Improved Tet-responsive promoters with minimized background expression. BMC Biotechnol. 2010, 10, 81. [CrossRef]

45. Chew, T.W.; Liu, X.J.; Liu, L.; Spitsbergen, J.M.; Gong, Z.; Low, B.C. Crosstalk of Ras and Rho: Activation of RhoA abates Kras-induced liver tumorigenesis in transgenic zebrafish models. Oncogene 2014, 33, 2717-2727. [CrossRef] [PubMed]

46. Li, Z.; Huang, X.; Zhan, H.; Zeng, Z.; Li, C.; Spitsbergen, J.M.; Meierjohann, S.; Schartl, M.; Gong, Z. Inducible and repressable oncogene-addicted hepatocellular carcinoma in Tet-on xmrk transgenic zebrafish. J. Hepatol. 2012, 56, 419-425. [CrossRef]

47. Li, Z.; Zheng, W.; Wang, Z.; Zeng, Z.; Zhan, H.; Li, C.; Zhou, L.; Yan, C.; Spitsbergen, J.M.; Gong, Z. A transgenic zebrafish liver tumor model with inducible Myc expression reveals conserved Myc signatures with mammalian liver tumors. Dis. Models Mech. 2013, 6, 414-423. [CrossRef] [PubMed]

48. Monroe, J.D.; Basheer, F.; Gibert, Y. Xmrks the Spot: Fish Models for Investigating Epidermal Growth Factor Receptor Signaling in Cancer Research. Cells 2021, 10, 1132. [CrossRef]

49. Berasain, C.; Ujue Latasa, M.; Urtasun, R.; Goni, S.; Elizalde, M.; Garcia-Irigoyen, O.; Azcona, M.; Prieto, J.; Avila, M.A. Epidermal Growth Factor Receptor (EGFR) Crosstalks in Liver Cancer. Cancers 2011, 3, 2444-2461. [CrossRef] [PubMed]

50. Wang, Y.; Wu, M.C.; Sham, J.S.; Zhang, W.; Wu, W.Q.; Guan, X.Y. Prognostic significance of c-myc and AIB1 amplification in hepatocellular carcinoma. A broad survey using high-throughput tissue microarray. Cancer 2002, 95, 2346-2352. [CrossRef] [PubMed]

51. Thorgeirsson, S.S.; Santoni-Rugiu, E. Transgenic mouse models in carcinogenesis: Interaction of c-myc with transforming growth factor alpha and hepatocyte growth factor in hepatocarcinogenesis. Br. J. Clin. Pharmacol. 1996, 42, 43-52. [CrossRef] [PubMed]

52. Conner, E.A.; Lemmer, E.R.; Sanchez, A.; Factor, V.M.; Thorgeirsson, S.S. E2F1 blocks and c-Myc accelerates hepatic ploidy in transgenic mouse models. Biochem. Biophys. Res. Commun. 2003, 302, 114-120. [CrossRef]

53. Sun, L.; Nguyen, A.T.; Spitsbergen, J.M.; Gong, Z. Myc-induced liver tumors in transgenic zebrafish can regress in tp53 null mutation. PLoS ONE 2015, 10, e0117249. [CrossRef]

54. Yang, Q.; Yan, C.; Gong, Z. Activation of liver stromal cells is associated with male-biased liver tumor initiation in xmrk and Myc transgenic zebrafish. Sci. Rep. 2017, 7, 10315. [CrossRef]

55. Yan, C.; Yang, Q.; Shen, H.M.; Spitsbergen, J.M.; Gong, Z. Chronically high level of tgfb1a induction causes both hepatocellular carcinoma and cholangiocarcinoma via a dominant Erk pathway in zebrafish. Oncotarget 2017, 8, 77096-77109. [CrossRef]

56. Nguyen, A.T.; Koh, V.; Spitsbergen, J.M.; Gong, Z. Development of a conditional liver tumor model by mifepristone-inducible Cre recombination to control oncogenic kras V12 expression in transgenic zebrafish. Sci. Rep. 2016, 6, 19559. [CrossRef]

57. Nakayama, J.; Lu, J.W.; Makinoshima, H.; Gong, Z. A Novel Zebrafish Model of Metastasis Identifies the HSD11beta1 Inhibitor Adrenosterone as a Suppressor of Epithelial-Mesenchymal Transition and Metastatic Dissemination. Mol. Cancer Res. 2020, 18, 477-487. [CrossRef]

58. Lu, J.-W.; Sun, Y.; Lin, L.-I.; Liu, D.; Gong, Z. Exacerbation of Liver Tumor Metastasis in twist1a+/xmrk+ Double Transgenic Zebrafish Following Lipopolysaccharide or Dextran Sulphate Sodium Exposure. Pharmaceuticals 2021, 14, 867. [CrossRef]

59. Yan, C.; Yang, Q.; Gong, Z. Tumor-Associated Neutrophils and Macrophages Promote Gender Disparity in Hepatocellular Carcinoma in Zebrafish. Cancer Res. 2017, 77, 1395-1407. [CrossRef]

60. Li, Y.; Li, H.; Spitsbergen, J.M.; Gong, Z. Males develop faster and more severe hepatocellular carcinoma than females in kras(V12) transgenic zebrafish. Sci. Rep. 2017, 7, 41280. [CrossRef] [PubMed]

61. Yang, Q.; Yan, C.; Yin, C.; Gong, Z. Serotonin Activated Hepatic Stellate Cells Contribute to Sex Disparity in Hepatocellular Carcinoma. Cell. Mol. Gastroenterol. Hepatol. 2017, 3, 484-499. [CrossRef]

62. Li, Z.; Zheng, W.; Li, H.; Li, C.; Gong, Z. Synergistic Induction of Potential Warburg Effect in Zebrafish Hepatocellular Carcinoma by Co-Transgenic Expression of Myc and xmrk Oncogenes. PLoS ONE 2015, 10, e0132319. [CrossRef] [PubMed]

63. Hoshida, Y.; Nijman, S.M.; Kobayashi, M.; Chan, J.A.; Brunet, J.P.; Chiang, D.Y.; Villanueva, A.; Newell, P.; Ikeda, K.; Hashimoto, M.; et al. Integrative transcriptome analysis reveals common molecular subclasses of human hepatocellular carcinoma. Cancer Res. 2009, 69, 7385-7392. [CrossRef] [PubMed] 
64. Li, Z.; Luo, H.; Li, C.; Huo, X.; Yan, C.; Huang, X.; Al-Haddawi, M.; Mathavan, S.; Gong, Z. Transcriptomic analysis of a transgenic zebrafish hepatocellular carcinoma model reveals a prominent role of immune responses in tumour progression and regression. Int. J. Cancer 2014, 135, 1564-1573. [CrossRef]

65. Subramanian, A.; Tamayo, P.; Mootha, V.K.; Mukherjee, S.; Ebert, B.L.; Gillette, M.A.; Paulovich, A.; Pomeroy, S.L.; Golub, T.R.; Lander, E.S.; et al. Gene set enrichment analysis: A knowledge-based approach for interpreting genome-wide expression profiles. Proc. Natl. Acad. Sci. USA 2005, 102, 15545-15550. [CrossRef] [PubMed]

66. Zheng, W.; Li, Z.; Nguyen, A.T.; Li, C.; Emelyanov, A.; Gong, Z. Xmrk, kras and myc transgenic zebrafish liver cancer models share molecular signatures with subsets of human hepatocellular carcinoma. PLoS ONE 2014, 9, e91179. [CrossRef]

67. Yan, C.; Yang, Q.; Huo, X.; Li, H.; Zhou, L.; Gong, Z. Chemical inhibition reveals differential requirements of signaling pathways in kras(V12)- and Myc-induced liver tumors in transgenic zebrafish. Sci. Rep. 2017, 7, 45796. [CrossRef] [PubMed]

68. Min, L.; He, B.; Hui, L. Mitogen-activated protein kinases in hepatocellular carcinoma development. Semin. Cancer Biol. 2011, 21, 10-20. [CrossRef]

69. Wang, W.; Smits, R.; Hao, H.; He, C. Wnt/beta-Catenin Signaling in Liver Cancers. Cancers 2019, 11, 926. [CrossRef]

70. He, S.; Tang, S. WNT/beta-catenin signaling in the development of liver cancers. Biomed. Pharmacother. 2020, $132,110851$. [CrossRef]

71. Kunst, C.; Haderer, M.; Heckel, S.; Schlosser, S.; Müller, M. The p53 family in hepatocellular carcinoma. Transl. Cancer Res. 2016, 5, 632-638. [CrossRef]

72. Link, T.; Iwakuma, T. Roles of p53 in extrinsic factor-induced liver carcinogenesis. Hepatoma Res. 2017, 3, 95-104. [CrossRef]

73. Zhan, P.; Ji, Y.N.; Yu, L.K. TP53 mutation is associated with a poor outcome for patients with hepatocellular carcinoma: Evidence from a meta-analysis. Hepatobiliary Surg. Nutr. 2013, 2, 260-265. [PubMed]

74. Morse, M.A.; Sun, W.; Kim, R.; He, A.R.; Abada, P.B.; Mynderse, M.; Finn, R.S. The Role of Angiogenesis in Hepatocellular Carcinoma. Clin. Cancer Res. 2019, 25, 912-920. [CrossRef]

75. Mousa, A.B. Sorafenib in the treatment of advanced hepatocellular carcinoma. Saudi J. Gastroenterol. 2008, 14, 40-42. [CrossRef] [PubMed]

76. Feng, J.; Li, J.; Wu, L.; Yu, Q.; Ji, J.; Wu, J.; Dai, W.; Guo, C. Emerging roles and the regulation of aerobic glycolysis in hepatocellular carcinoma. J. Exp. Clin. Cancer Res. 2020, 39, 126. [CrossRef]

77. Yang, Y.; Li, C.; Nie, X.; Feng, X.; Chen, W.; Yue, Y.; Tang, H.; Deng, F. Metabonomic studies of human hepatocellular carcinoma using high-resolution magic-angle spinning $1 \mathrm{H}$ NMR spectroscopy in conjunction with multivariate data analysis. J. Proteome Res. 2007, 6, 2605-2614. [CrossRef]

78. Beyoglu, D.; Imbeaud, S.; Maurhofer, O.; Bioulac-Sage, P.; Zucman-Rossi, J.; Dufour, J.F.; Idle, J.R. Tissue metabolomics of hepatocellular carcinoma: Tumor energy metabolism and the role of transcriptomic classification. Hepatology 2013, 58, 229-238. [CrossRef]

79. Desai, S.; Ding, M.; Wang, B.; Lu, Z.; Zhao, Q.; Shaw, K.; Yung, W.K.; Weinstein, J.N.; Tan, M.; Yao, J. Tissue-specific isoform switch and DNA hypomethylation of the pyruvate kinase PKM gene in human cancers. Oncotarget 2014, 5, 8202-8210. [CrossRef]

80. Jessy, T. Immunity over inability: The spontaneous regression of cancer. J. Nat. Sci. Biol. Med. 2011, 2, 43-49. [CrossRef] [PubMed]

81. Weinstein, I.B.; Joe, A. Oncogene addiction. Cancer Res. 2008, 68, 3077-3080; discussion 3080. [CrossRef] [PubMed]

82. Li, Y.; Agrawal, I.; Gong, Z. Reversion of tumor hepatocytes to normal hepatocytes during liver tumor regression in an oncogeneexpressing transgenic zebrafish model. Dis. Models Mech. 2019, 12, dmm039578. [CrossRef]

83. Hou, J.; Zhang, H.; Sun, B.; Karin, M. The immunobiology of hepatocellular carcinoma in humans and mice: Basic concepts and therapeutic implications. J. Hepatol. 2020, 72, 167-182. [CrossRef]

84. Roderburg, C.; Wree, A.; Demir, M.; Schmelzle, M.; Tacke, F. The role of the innate immune system in the development and treatment of hepatocellular carcinoma. Hepat. Oncol. 2020, 7, HEP17. [CrossRef]

85. Wang, S.Z.; Lee, S.D.; Sarkar, D.; Lee, H.M.; Khan, A.; Bhati, C.; Sharma, A.; Kumaran, V.; Bruno, D.; Cotterell, A.; et al. Immunological characterization of hepatocellular carcinoma. Hepatoma Res. 2021, 7, 6.

86. Hall, C.; Flores, M.V.; Storm, T.; Crosier, K.; Crosier, P. The zebrafish lysozyme C promoter drives myeloid-specific expression in transgenic fish. BMC Dev. Biol 2007, 7, 42. [CrossRef] [PubMed]

87. Ellett, F.; Pase, L.; Hayman, J.W.; Andrianopoulos, A.; Lieschke, G.J. mpeg1 promoter transgenes direct macrophage-lineage expression in zebrafish. Blood 2011, 117, e49-e56. [CrossRef]

88. Yan, C.; Huo, X.; Wang, S.; Feng, Y.; Gong, Z. Stimulation of hepatocarcinogenesis by neutrophils upon induction of oncogenic kras expression in transgenic zebrafish. J. Hepatol. 2015, 63, 420-428. [CrossRef] [PubMed]

89. Yang, Q.; Yan, C.; Gong, Z. Interaction of hepatic stellate cells with neutrophils and macrophages in the liver following oncogenic kras activation in transgenic zebrafish. Sci. Rep. 2018, 8, 8495. [CrossRef]

90. Zhao, Y.; Huang, X.; Ding, T.W.; Gong, Z. Enhanced angiogenesis, hypoxia and neutrophil recruitment during Myc-induced liver tumorigenesis in zebrafish. Sci. Rep. 2016, 6, 31952. [CrossRef]

91. Huo, X.; Li, H.; Li, Z.; Yan, C.; Agrawal, I.; Mathavan, S.; Liu, J.; Gong, Z. Transcriptomic profiles of tumor-associated neutrophils reveal prominent roles in enhancing angiogenesis in liver tumorigenesis in zebrafish. Sci. Rep. 2019, 9, 1509. [CrossRef]

92. Yan, C.; Yang, Q.; Gong, Z. Transgenic expression of tgfb1a induces hepatic inflammation, fibrosis and metastasis in zebrafish. Biochem. Biophys. Res. Commun. 2019, 509, 175-181. [CrossRef] 
93. Helal, M.; Yan, C.; Gong, Z. Stimulation of hepatocarcinogenesis by activated cholangiocytes via Il17a/f1 pathway in kras transgenic zebrafish model. Sci. Rep. 2021, 11, 1372. [CrossRef]

94. Hefaiedh, R.; Ennaifer, R.; Romdhane, H.; Ben Nejma, H.; Arfa, N.; Belhadj, N.; Gharbi, L.; Khalfallah, T. Gender difference in patients with hepatocellular carcinoma. Tunis Med. 2013, 91, 505-508.

95. Wu, E.M.; Wong, L.L.; Hernandez, B.Y.; Ji, J.F.; Jia, W.; Kwee, S.A.; Kalathil, S. Gender differences in hepatocellular cancer: Disparities in nonalcoholic fatty liver disease/steatohepatitis and liver transplantation. Hepatoma Res. 2018, 4, 66. [CrossRef]

96. Natri, H.M.; Wilson, M.A.; Buetow, K.H. Distinct molecular etiologies of male and female hepatocellular carcinoma. BMC Cancer 2019, 19, 951. [CrossRef]

97. Li, H.; Lu, J.W.; Huo, X.; Li, Y.; Li, Z.; Gong, Z. Effects of sex hormones on liver tumor progression and regression in Myc/xmrk double oncogene transgenic zebrafish. Gen. Comp. Endocrinol. 2019, 277, 112-121. [CrossRef]

98. Li, H.; Li, Y.; Lu, J.W.; Huo, X.; Gong, Z. Liver-specific androgen receptor knockout attenuates early liver tumor development in zebrafish. Sci. Rep. 2019, 9, 10645. [CrossRef]

99. Dhanapal, R.; Saraswathi, T.; Govind, R.N. Cancer cachexia. J. Oral Maxillofac. Pathol. 2011, 15, 257-260. [CrossRef] [PubMed]

100. Baracos, V.E.; Martin, L.; Korc, M.; Guttridge, D.C.; Fearon, K.C.H. Cancer-associated cachexia. Nat. Rev. Dis. Primers 2018, 4, 17105. [CrossRef] [PubMed]

101. Baldwin, C.; Spiro, A.; Ahern, R.; Emery, P.W. Oral nutritional interventions in malnourished patients with cancer: A systematic review and meta-analysis. J. Natl. Cancer Inst. 2012, 104, 371-385. [CrossRef] [PubMed]

102. Safdie, F.M.; Dorff, T.; Quinn, D.; Fontana, L.; Wei, M.; Lee, C.; Cohen, P.; Longo, V.D. Fasting and cancer treatment in humans: A case series report. Aging 2009, 1, 988-1007. [CrossRef]

103. Zhong, Z.; Sanchez-Lopez, E.; Karin, M. Autophagy, Inflammation, and Immunity: A Troika Governing Cancer and Its Treatment. Cell 2016, 166, 288-298. [CrossRef] [PubMed]

104. Yang, Q.; Yan, C.; Wang, X.; Gong, Z. Leptin induces muscle wasting in a zebrafish kras-driven hepatocellular carcinoma (HCC) model. Dis. Models Mech. 2019, 12, dmm038240. [CrossRef] [PubMed]

105. Kelesidis, T.; Kelesidis, I.; Chou, S.; Mantzoros, C.S. Narrative review: The role of leptin in human physiology: Emerging clinical applications. Ann. Intern. Med. 2010, 152, 93-100. [CrossRef] [PubMed]

106. Taylor, K.L.; Grant, N.J.; Temperley, N.D.; Patton, E.E. Small molecule screening in zebrafish: An in vivo approach to identifying new chemical tools and drug leads. Cell Commun. Signal. 2010, 8, 11. [CrossRef] [PubMed]

107. Zhang, T.; Peterson, R.T. Zebrafish as a Platform for Drug Screening. In The Zebrafish in Biomedical Research; Cartner, S.C., Eisen, J.S., Farmer, S.C., Guillemin, K.J., Kent, M.L., Sanders, G.E., Eds.; Academic Press: Cambridge, MA, USA, 2020; pp. 659-675.

108. Huang, X.; Nguyen, A.T.; Li, Z.; Emelyanov, A.; Parinov, S.; Gong, Z. One Step Forward: The Use of Transgenic Zebrafish Tumor Model in Drug Screens. Birth Defects Res. C 2011, 93, 173-181. [CrossRef]

109. Cully, M. Zebrafish earn their drug discovery stripes. Nat. Rev. Drug Discov. 2019, 18, 811-813. [CrossRef]

110. Patton, E.E.; Zon, L.I.; Langenau, D.M. Zebrafish disease models in drug discovery: From preclinical modelling to clinical trials. Nat. Rev. Drug Discov. 2021, 20, 611-628. [CrossRef] [PubMed]

111. North, T.E.; Goessling, W.; Walkley, C.R.; Lengerke, C.; Kopani, K.R.; Lord, A.M.; Weber, G.J.; Bowman, T.V.; Jang, I.-H.; Grosser, T.; et al. Prostaglandin E2 regulates vertebrate haematopoietic stem cell homeostasis. Nature 2007, 447, $1007-1011$. [CrossRef]

112. Goessling, W.; Allen, R.S.; Guan, X.; Jin, P.; Uchida, N.; Dovey, M.; Harris, J.M.; Metzger, M.E.; Bonifacino, A.C.; Stroncek, D.; et al. Prostaglandin E2 enhances engraftment of human cord blood stem cells and shows long-term safety in preclinical non-human primate transplant models. Cell Stem Cell 2011, 8, 445-458. [CrossRef]

113. Cutler, C.; Multani, P.; Robbins, D.; Kim, H.T.; Le, T.; Hoggatt, J.; Pelus, L.M.; Desponts, C.; Chen, Y.-B.; Rezner, B.; et al. Prostaglandin-modulated umbilical cord blood hematopoietic stem cell transplantation. Blood 2013, 122, 3074-3081. [CrossRef]

114. Mandelbaum, J.; Shestopalov, I.A.; Henderson, R.E.; Chau, N.G.; Knoechel, B.; Wick, M.J.; Zon, L.I. Zebrafish blastomere screen identifies retinoic acid suppression of $M Y B$ in adenoid cystic carcinoma. J. Exp. Med. 2018, 215, 2673-2685. [CrossRef]

115. Yang, Q.; Salim, L.; Yan, C.; Gong, Z. Rapid Analysis of Effects of Environmental Toxicants on Tumorigenesis and Inflammation Using a Transgenic Zebrafish Model for Liver Cancer. Mar. Biotechnol. 2019, 21, 396-405. [CrossRef] [PubMed]

116. Chen, S.; Dang, Y.; Gong, Z.; Letcher, R.J.; Liu, C. Progression of liver tumor was promoted by tris(1,3-dichloro-2-propyl) phosphate through the induction of inflammatory responses in kras transgenic zebrafish. Environ. Pollut. 2019, 255, 113315. [CrossRef]

117. Chen, S.; Gong, Z.; Letcher, R.J.; Liu, C. Promotion effect of liver tumor progression in male kras transgenic zebrafish induced by tris (1, 3-dichloro-2-propyl) phosphate. Ecotoxicol. Environ. Saf. 2020, 191, 110220. [CrossRef] [PubMed]

118. Zhu, Y.; Yang, D.; Duan, X.; Zhang, Y.; Chen, D.; Gong, Z.; Liu, C. Perfluorooctane sulfonate promotes doxycycline-induced liver tumor progression in male Kras(v12) transgenic zebrafish. Environ. Res. 2021, 196, 110962. [CrossRef] [PubMed]

119. Argiles, J.M.; Busquets, S.; Stemmler, B.; Lopez-Soriano, F.J. Cancer cachexia: Understanding the molecular basis. Nat. Rev. Cancer 2014, 14, 754-762. [CrossRef]

120. Springer, J.; Tschirner, A.; Haghikia, A.; von Haehling, S.; Lal, H.; Grzesiak, A.; Kaschina, E.; Palus, S.; Potsch, M.; von Websky, K.; et al. Prevention of liver cancer cachexia-induced cardiac wasting and heart failure. Eur. Heart J. 2014, 35, 932-941. [CrossRef] 